\title{
Hubungan antara Kunjungan Ibu Hamil, Persalinan Ditolong Tenaga Kesehatan, dan Pelayanan Kesehatan Ibu Nifas Dengan Angka Kematian Ibu (AKI)
}

\author{
Nita Dewi Mardiana, Siti Nurrochmah*, Septa Katmawanti \\ Universitas Negeri Malang, Jl. Semarang No. 5 Malang, Jawa Timur, Indonesia \\ *Penulis korespondensi, Surel: siti.nurrochmah.fik@um.ac.id
}

Paper received: 8-11-2021; revised: 21-11-2021; accepted: 24-11-2021

\begin{abstract}
Maternal be the one of important that means it need serious handling. Almost every two minute, in someplace at world, a woman die because maternal complication and labor. At year 2016, maternal mortality rate in the East Java Province reaching 91,000 every 100.000 live birth. This number experiences has been rising compared year 2015 that reach 89,6 every 100.000 live birth. Maternal health service when pregnant until postnatal become important effort for reducing maternal mortality rate. Increasing mortality rate in year 2016 followed by decreasing of antenatal care, health care delivery, and postpartum health care. This research intended to know correlation between antenatal care, health care delivery, and postpartum health care with maternal mortality rate in the east java province years 2017. This research is correlational research with a data using a secondary data that obtained from Health agency east java province. Data analyses use pearson-product moment with helped of Microsoft Excel. Population from this research is all of East Java Province. Result of this research founding significant result between antenatal care and health care delivery with maternal mortality rate and direction negative relation. Different with that two variable, This research result also show there is no significant between postpartum health care services with maternal mortality rate and positive course of relation. Based on the research result, can be concluded that the range of antenatal care and health care delivery will be followed by decreasing of maternal mortality rate in a significant manner.
\end{abstract}

Keywords: maternal mortality rate; antenatal care; health care delivery

\begin{abstract}
Abstrak
Angka Kematian Ibu (AKI) menjadi salah satu isu penting yang artinya memerlukan penanganan serius dalam upaya pencegahannya. Hampir setiap dua menit, di suatu tempat di dunia, seorang wanita meninggal karena komplikasi kehamilan dan persalinan. Tahun 2016, AKI di Jawa Timur meningkat di angka 91,00 bila dibandingkan tahun sebelumnya di 89,6. Pelayanan di bidang kesehatan ibu selama masa kehamilan, persalinan, hingga nifas menjadi penting sebagai upaya penurunan AKI. Meningkatnya AKI pada tahun 2016 diikuti dengan menurunnya kunjungan ibu hamil(antenatal), persalinan ditolong tenaga kesehatan (linakes), dan pelayanan kesehatan ibu nifas (yankes nifas). Tujuan dilakukannya penelitian untuk mengetahui hubungan kunjungan antenatal, linakes, dan yankes nifas dengan AKI di Provinsi Jawa Timur tahun 2017. Penelitian ini merupakan penelitian korelasional dengan data yang dipakai merupakan data sekunder yang diperoleh dari hasil pencatatan pada Dinkes Jatim. Analisis data menggunakan uji pearson-product moment dengan bantuan Microsoft Excel. Populasi dari penelitian ini adalah seluruh kabupaten dan kota di Provinsi Jawa Timur. Hasil penelitian menunjukkan terdapat hubungan yang signifikan antara kunjungan entenatal dan linakes dengan AKI, serta hubungan yang tidak signifikan antara yankes nifas dengan AKI. Berdasarkan hasil penelitian, dapat disimpulkan bahwa peningkatan cakupan kunjungan ibu hamil dan persalinan ditolong tenaga kesehatan akan diikuti oleh penurunan AKI secara signifikan, begitu juga sebaliknya.
\end{abstract}

Kata kunci: angka kematian ibu; kunjungan antenatal; persalinan 


\section{Pendahuluan}

Situasi derajat kesehatan digambarkan ke dalam empat indikator pembangunan kesehatan, diantaranya adalah angka kematian (mortalitas) (Dinkes Jatim, 2015). Kematian ibu menjadi salah satu isu penting yang artinya memerlukan penanganan serius dalam upaya pencegahannya. Setiap jam, satu perempuan meninggal dunia pada saat melahirkan atau karena sebab-sebab yang ada hubungannya dengan kehamilan (UNICEF Indonesia, 2012). Hampir setiap dua menit, di suatu tempat di dunia, seorang wanita meninggal karena komplikasi kehamilan dan persalinan (Lawson \& Keirse, 2013). Keberhasilan upaya kesehatan ibu dapat dilihat melalui indikator AKI (Kemenkes RI, 2017).

AKI merupakan jumlah kematian bunda sepanjang kehamilan sampai nifas dan diakibatkan oleh hamil, bersalin, serta nifas ataupun penanganannya namun bukan sebabsebab lain semacam musibah atau sebagainya tiap seratus ribu kelahiran hidup (Kemenkes RI, 2016). Upaya penurunan AKI termasuk ke dalam tujuan ketiga dalam program SDGs dengan target mengurangi perbandingan angka kematian pada kehamilan hingga di bawah 70 setiap 100.000 jumlah lahir hidup (Kementerian Perencanaan Pembangunan Nasional, 2017). Upaya penurunan AKI di Indonesia hingga tahun 2016 belum bisa mencapai target yang telah ditetapkan dalam SDGs. Jawa Timur hingga tahun 2012 termasuk ke dalam enam penyumbang AKI terbesar di Indonesia (Kemenkes RI, 2014).

Ada tiga indikator yang mempengaruhi AKI secara langsung, diantaranya kunjungan antenatal, linakes, dan yankes nifas (Nurrizka \& Saputra, 2013). Pelayanan antenatal pada kunjungan ibu hamil berperan penting sebagai pendeteksi dan pelaksanaan dini komplikasi yang mungkin muncul ketika masa bersalin (Kemenkes RI, 2014). Selain kunjungan ibu hamil, linakes terbukti berkontribusi terhadap resiko kematian ibu (Kemenkes RI, 2016). Tidak ada jaminan keselamatan pada pertolongan persalinan di luar fasilitas pelayanan kesehatan tanpa tenaga kesehatan terlatih, sehingga meningkatkan resiko persalinan yang tidak aman. Pelayanan kesehatan ibu nifas juga memiliki peran yang sama sebagai indikator penurunan AKI, yang perawatannya paling sedikit dilakukan tiga kali dengan arahan petugas kesehatan (Kemenkes RI, 2016).

AKI di Jawa Timur pada 2016 meningkat ke angka 91,00 dibandingkan tahun 2015 di angka 89,6. Meningkatnya AKI diikuti dengan menurunnya kunjungan antenatal, linakes, dan yankes nifas. Kunjungan antenatal K1 pada 2015 di angka 98,75 persen menurun pada tahun 2016 di angka 97 persen, sementara untuk K4 pada 2015 di angka 91,24 persen menurun pada tahun 2016 di angka 89,53 persen. Cakupan persalinan oleh tenaga kesehatan yaitu dari 95,81 persen pada tahun 2015 menjadi 95,10 persen pada tahun 2016, sedangkan cakupan yankes nifas sebesar 94,8 persen pada tahun 2015 dan menurun di tahun 2016 dengan angka 93,8 persen(Dinkes Jatim, 2017).

Layanan kesehatan ibu selama masa kehamilan, persalinan, hingga nifas menjadi penting sebagai upaya penurunan AKI. Tujuan dilakukannya penelitian untuk mengetahui hubungan kunjungan antenatal, linakes, dan yankes nifas dengan AKI di Jawa Timur pada 2017.

\section{Metode}

Penelitian dilakukan dengan desain korelasional metode cross sectional. Data penelitian ini menggunakan data sekunder yang diambil dari Dinas Kesehatan Provinsi Jawa Timur berupa dokumen, dengan subjek penelitian adalah populasi wanita hamil hingga nifas di 38 kota dan kabupaten di Provinsi Jawa Timur pada tahun 2017. Data penelitian dikumpulkan dan 
dilakukan analisis univariat dan bivariat dengan bantuan software Microsoft Excel dan IBM SPSS Statistics 23 untuk mengetahui hubungan antara variabel bebas dengan variabel terikat. Penelitian ini menggunakan data AKI sebagai variabel terikat $(\mathrm{Y})$, dan kunjungan ibu masa kehamilan $\left(\mathrm{X}_{1}\right)$, persalinan oleh tenaga medis atau linakes $\left(\mathrm{X}_{2}\right)$, serta pelayanan kesehatan masa nifas $\left(\mathrm{X}_{3}\right)$ sebagai variabel bebas. Jumlah data yang dikumpulkan pada masing-masing variabel terdiri dari 38 kota dan kabupaten di Provinsi Jawa Timur.

Analisis univariat dilakukan untuk statistik deskriptif dengan menampilkan frekuensi dan persentase serta karakteristik masing-masing subjek pada variabel bebas penelitian serta hasil perhitungan variabel terikat AKI. Analisis bivariat dilakukan menggunakan PearsonProduct Moment dengan membandingkan nilai signifikansi > taraf signifikansi 5\%. Penelitian ini dilakukan dengan mendapat surat persetujuan penelitian dari dinas terkait (Dinas Kesehatan Provinsi Jawa Timur).

\section{Hasil dan Pembahasan}

Hasil penelitian ditunjukkan di bawah ini. Tabel 1 menunjukkan bahwa pada 2017 AKI di Jawa Timur meningkat sejumlah 0,92 dari tahun sebelumnya.

Tabel 1. Distribusi Frekuensi (DF) AKI

\begin{tabular}{cccc}
\hline Lahir Hidup & Kematian Ibu & Rata-rata & AKI \\
\hline 575.485 & 529 & 89,97 & 91,92 \\
\hline
\end{tabular}

Tabel 2 menunjukkan bahwa tidak semua ibu hamil melakukan kunjungan ke fasilitas pelayanan kesehatan selama masa kehamilan di Jawa Timur pada 2017.

Tabel 2. Distribusi Frekuensi (DF) Kunjungan Antenatal

\begin{tabular}{ccc}
\hline Wanita Hamil & K 1 & K 4 \\
\hline 633.034 & 621.643 & 569.281 \\
Rata-rata & 97,74 & 89,33 \\
Persentase & 98,20 & 89,93 \\
\hline
\end{tabular}

Tabel 3 menunjukkan bahwa tidak semua ibu bersalin melakukan persalinan di fasilitas pelayanan kesehatan dan memperoleh pelayanan kesehatan ibu nifas di Provinsi Jawa Timur pada tahun 2017.

Tabel 3. Distribusi Frekuensi (DF) Ibu Bersalin

\begin{tabular}{ccc}
\hline Ibu Bersalin & Linakes & Yankes Nifas \\
\hline 604.259 & 571.788 & 561.450 \\
Rata-rata & 94,05 & 98,30 \\
Persentase & 94,63 & 92,92 \\
\hline
\end{tabular}

Tabel 4 menunjukkan kesimpulan uji normal antar variabel (bebas dan terikat). Hasil uji normalitas menunjukkan seluruh variabel berdistribusi normal (nilai signifikansi $>$ taraf signifikansi 5\% ) sehingga telah memenuhi syarat dalam uji statistik parametrik dan pengujian hipotesis dilakukan dengan uji Product Moment (Pearson) dengan hasil seperti tabel 5. 
Tabel 4. Hasil Uji Normalitas

\begin{tabular}{lccc}
\hline \multicolumn{1}{c}{ Variabel } & $\begin{array}{c}\text { Nilai } \\
\text { Signifikansi }\end{array}$ & $\begin{array}{c}\text { Taraf } \\
\text { Signifikansi }\end{array}$ & Interpretasi \\
\hline Angka Kematian Ibu (AKI) & 0,200 & $>0,05$ & Data Berdistibusi Normal \\
Kunjungan Ibu Hamil & & & \\
K1 & 0,144 & $>0,05$ & Data Berdistibusi Normal \\
K4 & 0,200 & $>0,05$ & Data Berdistibusi Normal \\
Persalinan ditolong Tenaga & 0,200 & $>0,05$ & Data Berdistibusi Normal \\
Kesehatan & & & \\
Pelayanan Kesehatan Ibu Nifas & 0,107 & $>0,05$ & Data Berdistibusi Normal \\
\hline
\end{tabular}

Tabel 5 menunjukkan adanya hubungan yang signifikan dengan nilai Sig $<0,05$ antara kunjungan ibu hamil dengan AKI (sig K1=0,34 dan sig K4=0,17). Nilai korelasi menunjukkan arah hubungan negatif, artinya semakin tinggi nilai cakupan kunjungan ibu hamil akan diikuti dengan semakin rendahnya nilai AKI dan begitu juga sebaliknya. Tidak berhenti pada kontak pertama ibu hamil dengan petugas kesehatan pada masa awal kehamilan, nilai signifikansi kunjungan lengkap yang lebih tinggi menunjukkan pentingnya pemeriksaan ibu hamil sesuai standar yang dilakukan secara berkala. Tabel 5 menunjukkan adanya hubungan yang signifikan dengan nilai $(\operatorname{sig} 0,393<0,05)$ antara persalinan ditolong tenaga kesehatan dengan AKI. Nilai korelasi menunjukkan arah hubungan negatif, artinya semakin tinggi nilai cakupan persalinan ditolong tenaga kesehatan akan diikuti dengan semakin rendahnya nilai AKI dan begitu sebaliknya. Melihat pentingnya masa persalinan, tenaga persalinan yang terlatih dapat menjadi pilihan terbaik dalam upaya meminimalisir atau menangani komplikasi selama masa persalinan dengan perawatan yang benar. Tabel 5 menunjukkan adanya hubungan yang tidak signifikan dengan nilai (sig 0,209>0,05) antara pelayanan kesehatan ibu nifas dengan AKI. Nilai korelasi menunjukkan arah hubungan positif, artinya semakin tinggi nilai pelayanan kesehatan ibu nifas akan diikuti dengan tingginya nilai AKI dan begitu juga sebaliknya. Hasil yang berbanding terbalik dengan teori yang ada dapat dikarenakan karena beberapa hal, diantaranya adalah pelayanan kesehatan yang sudah baik pada masa pra persalinan hingga masa persalinan, sehingga sedikit perawatan yang dilakukan pada ibu masa nifas sudah cukup untuk membantu proses pemulihan ibu bersalin. Pengelolaan masa nifas yang baik yang dilakukan ibu secara mandiri juga dapat menjadi penyebab hubungan antara pelayanan kesehatan ibu nifas dengan AKI tidak signifikan.

Tabel 5. Hasil Analisis Uji Hipotesis Hubungan Variabel Bebas dengan AKI

\begin{tabular}{lccccc}
\hline Variabel Bebas & $\begin{array}{c}\text { Koefisien } \\
\text { Korelasi }\end{array}$ & $\begin{array}{c}\text { Nilai } \\
\text { Sig }\end{array}$ & $\begin{array}{c}\text { Taraf } \\
\text { Sig }\end{array}$ & $\begin{array}{c}\text { Uji } \\
\text { Hipotesis }\end{array}$ & Interpretasi \\
\hline Kunjungan Ibu & & & & & \\
Hamil & $-0,345$ & 0,34 & 0,05 & Sig $<0,05$ & Ada hubungan yang signifikan \\
K1 & $-0,383$ & 0,17 & 0,05 & Sig $<0,05$ & $\begin{array}{c}\text { Ada hubungan yang signifikan } \\
\text { K4 }\end{array}$ \\
$\begin{array}{l}\text { Persalinan } \\
\text { ditolong Tenaga }\end{array}$ & $-0,393$ & 0,015 & 0,05 & Sig $<0,05$ & Ada hubungan yang signifikan \\
$\begin{array}{l}\text { Kesehatan } \\
\begin{array}{l}\text { Pelayanan } \\
\text { Kesehatan Nifas }\end{array}\end{array}$ & 0,209 & 0,209 & 0,05 & Sig $>0,05$ & $\begin{array}{c}\text { Tidak ada hubungan yang } \\
\text { signifikan }\end{array}$ \\
\hline
\end{tabular}




\subsection{Hubungan antara Kunjungan Ibu Hamil dengan AKI}

Kunjungan ibu hamil untuk memperoleh pelayanan antenatal bertujuan sebagai pendeteksi dini komplikasi pada ibu hamil melalui kontak dengan petugas kesehatan mulai trimester pertama agar ibu hamil mendapatkan pelayanan yang berkualitas. Pelayanan ini termasuk minimal satu kali diperiksa oleh tenaga kesehatan ahli (dokter) (Dinkes Jawa Timur, 2018). Komplikasi selama masa kehamilan merupakan salah satu penyebab morbiditas dan mortalitas pada ibu hamil. (WHO, 2016). Tujuan pelayanan antenatal pada setiap kunjungan ibu hamil adalah dapat mencegah serta meminimalisir terjadinya morbiditas dan mortalitas pada ibu hamil pada masa kehamilan hingga menjelang persalinan.

Standar kunjungan ibu hamil selama masa kehamilan untuk memperoleh pelayanan antenatal tidak hanya berhenti pada kunjungan pertama ibu hamil (K1). Standar yang telah ditentukan agar pelayanan ibu hamil optimal dan berkualitas adalah sebanyak minimal empat kali selama masa kehamilan dengan kunjungan lengkap ibu hamil (K4) sesuai jadwal (Fitrayeni, Suryati, \& Faranti, 2015). Beberapa komplikasi yang sering terjadi pada kehamilan diantaranya adalah diabetes gestasional, hipertensi gestasional, pre eklamsia, kehamilan ektopik, pendarahan, plasenta previa dan keguguran (Duong, Davis, \&Falhammar, 2015; Saraswat dkk, 2016). Melalui kunjungan ibu hamil yang dilakukan selama masa kehamilan, ibu hamil dapat memperoleh informasi penting seputar kehamilan, termasuk masalah yang timbul pada masa kehamilan baik pada ibu maupun janin secara dini sehingga memungkinkan petugas kesehatan dapat memberikan pertolongan lebih cepat (Nahak, 2017).

Berdasarkan data hasil penelitian yang telah dilakukan menunjukkan terdapat hubungan yang signifikan antara kunjungan pertama antenatal (K1) dan kunjungan lengkap antenatal (K4) dengan AKI di Jawa Timur pada 2017. Nilai korelasi menunjukkan arah hubungan negatif, artinya semakin tinggi nilai cakupan kunjungan ibu hamil maka akan diikuti dengan semakin rendahnya nilai Angka Kematian Ibu (AKI) dan begitu juga sebaliknya. Hasil penelitian ini sejalan dengan penelitian Nurrizka dan Wahyono dengan nilai secara berturutturut $\mathrm{p} \leq 0.001$ (berhubungan signifikan) yang menunjukkan bahwa wilayah dengan cakupan K1 dan K4 yang rendah memiliki AKI tinggi. Sebaliknya wilayah dengan cakupan K1 dan K4 yang tinggi memiliki AKI rendah (Nurrizka \& Wahyono, 2018). Hal ini sesuai penelitian Suriani dengan nilai $\mathrm{p}=0,000$ menyatakan kunjungan ibu hamil berhubungan dengan kematian ibu (Suriani, 2017). Persentase kunjungan lengkap ibu hamil (K4) mempengaruhi Angka Kematian Ibu (AKI) secara signifikan (Arkandi \& Winahju, 2015).

Hasil penelitian Ahmalia dan Parmisze juga menyatakan pengetahuan ibu tentang kehamilan berhubungan dengan penentuan sikap terhadap kepatuhan kunjungan ibu selama masa kehamilan (Ahmalia \& Parmisze, 2018). Penelitian Ningrum menyebutkan pengetahuan merupakan faktor yang mempengaruhi perilaku dalam penerimaan informasi kesehatan (Ningrum, 2019). Mudahnya penerimaan informasi kesehatan dari tenaga ahli berdampak pada kepatuhan kunjungan ibu hamil. Semakin baik pengetahuan ibu maka semakin baik pula ibu memanfaatkan pelayanan antenatal sehingga dapat meminimalisir AKI (Djonis, 2015). Kepatuhan kunjungan ibu hamil selama masa kehamilan dilakukan dengan mengikuti program dan kegiatan sesuai saran yang diberikan oleh tenaga kesehatan. Manfaat yang diterima adalah banyak mendapat informasi penting seputar kehamilan, termasuk masalah yang timbul pada masa kehamilan baik pada ibu maupun janin secara dini sehingga memungkinkan petugas kesehatan dapat memberikan pertolongan lebih cepat (Nahak, 2017). 


\subsection{Hubungan antara Persalinan Ditolong Tenaga Kesehatan dengan AKI}

Persiapan proses bersalin aman bertujuan supaya ibu serta keluarganya melakukan perencanaan tempat dan tenaga ahli yang membantu proses bersalin secara aman. Tempat dan penolong bersalin yang aman adalah dengan melakukan persalinan di fasilitas kesehatan dan ditolong oleh tenaga kesehatan (Kemenkes RI, 2014). Penyebab kematian ibu(langsung) mendekati sembilan puluh persen berlangsung tepat saat proses bersalin dan berlangsung sesaat setelah proses bersalin (Chalid, 2016). Salah satu upaya pencegahannya adalah melaksanakan persalinan yang ditolong oleh tenaga kesehatan di fasilitas kesehatan yang sesuai dengan Standar Pelayanan Program Kesehatan (Putro \& Maisya, 2015).

Berdasarkan data hasil penelitian yang telah dilakukan menunjukkan terdapat hubungan yang signifikan antara variabel persalinan ditolong tenaga kesehatan dengan AKI di Jawa Timur pada 2017. Tanda negatif pada nilai korelasi menunjukkan arah hubungan negatif, artinya semakin tinggi nilai cakupan persalinan ditolong tenaga kesehatan maka akan diikuti dengan semakin rendahnya nilai Angka Kematian Ibu (AKI) dan begitu juga sebaliknya. Hasil penelitian ini sejalan dengan penelitian lain yang menunjukkan nilai $p=0,001$ (berhubungan signifikan) yang menunjukkan bahwa wilayah dengan cakupan persalinan ditolong oleh tenaga kesehatan yang rendah memiliki Angka Kematian Ibu (AKI) tinggi (Suriani, 2017). Hasil ini sama seperti yang diteliti Nurrizka dan Wahyono, menghasilkan nilai ( $\mathrm{p} \leq 0.001$,berhubungan signifikan) sehingga menunjukkan tinggi rendahnya proses bersalin dengan bantuan tenaga ahli (medis) berhubungan dengan tinggi rendahnya kematian ibu (Nurrizka \& Wahyono, 2018). Hasil penelitian Sumarmi menunjukkan bahwa pertolongan persalinan yang dilakukan tenaga kesehatan terlatih adalah satu dari berbagai cara paling ampuh sebagai upaya penurunan AKI (Sumarmi, 2017). Penelitian dari berbagai tempat di dunia membuktikan hasil yang signifikan pada korelasi ini (pertolongan ibu bersalin dengan kematiannya) (Depkes RI dalam Nurhidayanti, Margawati, \& Irene, 2018).

Menteri Kesehatan menetapkan target capaian kinerja bagi pemerintah daerah dalam pelayanan kesehatan ibu bersalin adalah seratus persen. Target capaian kinerja ini merupakan standar pelayanan minimal yang harus dilakukan oleh pemerintah daerah (Menteri Kesehatan RI, 2016). Meskipun standar pelayanan telah ditetapkan, hasil di lapangan menunjukkan tidak semua bersalin melakukan persalinan sesuai dengan himbauan pemerintah. Berdasarkan data penelitian, masih ada sebagian persalinan ibu tidak didampingi oleh tenaga kesehatan di fasilitas pelayanan kesehatan. Hal ini ditunjukkan dengan hanya dua dari total tiga puluh delapan kota yang memiliki persentase seratus persen pada data persalinan ditolong tenaga kesehatan. Rata-rata persentase proses bersalin dengan bantuan tenaga ahli (medis) adalah 94,63 persen dari jumlah total sebesar 604.259 ibu bersalin.

Persalinan bila dilakukan tanpa bantuan tenaga ahli (medis) terlatih dan tidak dilakukan di fasilitas pelayanan resmi (rumah sakit dan sejenisnya) yang memadai dapat menimbulkan resiko tidak aman selama proses bersalin. Penyebabnya adalah tidak adanya jaminan keamanan yang diberikan baik bagi ibu bersalin maupun janinnya. Ada berbagai resiko yang ditimbulkan akibat persalinan yang tidak aman, sehingga dapat meningkatkan resiko morbiditas dan mortalitas baik ibu maupun janinnya. Salah satu penolong persalinan bukan tenaga kesehatan terlatih yang masih dipercaya oleh masyarakat adalah dukun bayi. Sebagian masyarakat masih memberikan kepercayaan terhadap dukun bayi sebagai salah satu pembantu persalinan yang aman karena telah secara turun-temurun berpengalaman dalam 
membantu proses bersalin masyarakat (Amalia, 2013). Peran dari masyarakat inilah yang mampu tetap menjaga eksistensi dukun bayi dalam pelayanan kesehatan tradisional.

\subsection{Hubungan antara Pelayanan Kesehatan Ibu Nifas dengan AKI}

Standar minimal pelayanan kesehatan masa nifas adalah sedikitnya empat kali yaitu pada enam hingga delapan jam pasca persalinan, enam hari pasca persalinan, minggu kedua, dan minggu keenam (Sukma, Hidayati, \& Jamil, 2017). Kunjungan pada masa nifas tersebut berfungsi sebagai media dalam memantau kondisi kesehatan ibu pasca persalinan guna mencegah, mendeteksi, dan menangani masalah kesehatan ibu nifas sehingga dapat meminimalisir morbiditas dan mortalitas ibu (Reinissa \& Indrawati, 2017).

Berdasarkan hasil penelitian yang telah dilakukan menunjukkan terdapat hubungan yang tidak signifikan antara variabel pelayanan kesehatan ibu nifas dengan AKI di Jawa Timur pada 2017. Tanda positif pada nilai korelasi menunjukkan arah hubungan positif, artinya semakin tinggi cakupan pelayanan kesehatan ibu nifas maka semakin tinggi pula Angka Kematian Ibu (AKI) dan begitu sebaliknya. Hasil ini tentu berbeda dengan asumsi(hipotesis) penelitian ini. Hasil ini menunjukkan yankes ibu pada masa nifas bukan termasuk ke dalam faktor utama penyebab kematian ibu. Hasil penelitian ini sejalan dengan hasil penelitian yang dilakukan oleh Rahmawati, Martini, dan Wahyuni dengan nilai $\mathrm{p}=0,632$ yang menunjukkan hubungan yang tidak signifikan antara yankes nifas dengan kejadian kematian ibu (Rahmawati, Martini, \& Wahyuni, 2014).

Menurut Windarti yang diperlukan wanita selama nifas adalah pelayanan kesehatan yang condong pada pemantauan dan menjaga kesehatan dengan menyampaikan informasi dan kecakapan kesehatan sesuai porsinya (Windarti, 2018). Pengelolaan kala nifas yang baik perlu dilakukan sebagai upaya penurunan AKI. Peran petugas kesehatan pada kala nifas adalah menghambat terjadinya pendarahan selama kurun waktu itu, menemukan tanda serta penanganan penyebab-penyebab pendarahan dan merujuk jika pendarahan tidak berhenti. Petugas kesehatan juga berperan dalam melakukan konsultasi seputar pencegahan pendarahan pasca bersalin (Kurniati, Nadyah, \& Darmawansyih, 2019). Kebutuhan ibu pada masa nifas terdiri dari nutrisi, proses eliminasi, personal higiene, ambulasi, aktivitas seksual, istirahat dan latihan atau senam nifas agar masa nifas berlangsung dengan baik (Islami \& Aisyaroh, 2012). Kemampuan ibu nifas dalam merawat luka pasca persalinan secara mandiri dan tepat, serta status gizi yang cukup bisa meningkatkan efektivitas kesembuhan luka. Hal ini bisa mengurangi resiko terjadi infeksi selama nifas (Jaelani, Putri, \& Lubis, 2017).

\section{Simpulan}

Simpulan dari penelitian ini yaitu ada hubungan yang signifikan antara kunjungan ibu hamil dengan Angka Kematian Ibu (AKI) di Provinsi Jawa Timur. Hasil dari penelitian ini juga menunjukkan ada hubungan yang signifikan antara persalinan oleh tenaga medis dengan AKI di Provinsi Jawa Timur. Hasil yang berbeda menunjukkan tidak ada hubungan(hubungan rendah) antara yankes nifas dengan AKI di Jawa Timur. Meninjau dari hasilnya, hal ini bisa membuka kesempatan eksplorasi pengetahuan untuk peneliti agar menemukan cara yang efisien bagi masalah kesehatan terutama AKI namun dengan sasaran atau faktor lain pada masa mendatang. Harapannya, penelitian ini bisa bermanfaat sebagai salah satu informasi serta bahan penilaian untuk Dinas Kesehatan Provinsi Jawa Timur sehingga dapat menerapkan 
kebijakan terkait upaya penurunan Angka Kematian Ibu (AKI) yang efektif sehingga nantinya bisa membantu dalam memperbaiki tingkat derajat kesehatan di Jawa Timur secara efisien.

\section{Daftar Rujukan}

Ahmalia, R. \& Parmisze, A. (2018). Hubungan Pengetahuan, Pendidikan dan Dukungan Suami dengan Kunjungan Pemeriksaan Antenatal Care di Puskesmas Lubuk Alung tahun 2017. Human Care Journal, 3(1), 12-20. doi: http://dx.doi.org/10.32883/hcj.v3i1.145.

Amalia, L. (2013). Faktor-Faktor yang Mempengaruhi Ibu dalam Pemilihan Penolong Persalinan. Journal Health and Sciences, 7(2), 1-11. Retrieved from http://ejurnal.ung.ac.id/index.php/ST/article/view $/ 1128$.

Arkandi, I \& Winahju, W.S. (2015). Analisis Faktor Risiko Kematian Ibu dan Kematian Bayi dengan Pendekatan Regresi Poisson Bivariat di Provinsi Jawa Timur Tahun 2013. Jurnal Sains dan Seni ITS, 4(2), 139-144. doi: 10.12962/j23373520.v4i2.9936.

Chalid, M.T. (2016). Upaya Menurunkan Angka Kematian Ibu: Peran Petugas Kesehatan. Gakken Health and Education Indonesia. Retrieved from: https://gakken-idn.id/topics/files/upaya-menurunkan-kema tian-ibu-peran-petugas-kesehatan-summary-full-text.pdf.

Dinas Kesehatan Provinsi Jawa Timur. (2015). Profil Kesehatan Provinsi Jawa Timur Tahun 2014. Surabaya: Dinas Kesehatan Provinsi Jawa Timur.

Dinas Kesehatan Provinsi Jawa Timur. (2018). Profil Kesehatan Provinsi Jawa Timur Tahun 2017. Surabaya: Dinas Kesehatan Provinsi Jawa Timur.

Djonis. (2015). Hubungan Pengetahuan dan Sikap Ibu Hamil dengan Pemanfaatan Antenatal Care di Puskesmas Kampung dalam Pontianak. Jurnal Vokasi Kesehatan, 1(1), 23-27.

Duong, V., Davis, B., Falhammar, H. (2015). Pregnancy and Neonatal Outcomes in Indigenous Australians with Diabetes in Pregnancy. World Journal of Diabetes, 6(6), 880-888. doi: 10.4239/wjd.v6.i6.880.

Fitrayeni, Suryati \& Faranti, R.M. (2015). Penyebab Rendahnya Kelengkapan Kunjungan Antenatal Care Ibu Hamil Di Wilayah Kerja Puskesmas Pegambiran. Jurnal Kesehatan Masyarakat Andalas, 10(1): 101-107.

Islami \& Aisyaroh, N. (2012). Efektifitas Kunjungan Nifas terhadap Pengurangan ketidaknyamanan Fisik yang terjadi pada Ibu Selama Masa Nifas. Jurnal Majalah Ilmiah Sultan Agung, 5(127), 1-15. Retrieved from http://jurnal.unissula.ac.id/index.php/majalahilmiahsultanagung/article/view/66.

Jaelani, A.K., Putri, M. \& Lubis, N.A. (2017). Hubungan Pengetahuan Ibu Nifas tentang Makanan Gizi Seimbang dengan Penyembuhan Luka Perineum. Journal Endurance, 2(1), 31-36. doi: http://dx.doi.org/10.22216/jen.v2i1.1120.

Kementerian Kesehatan Republik Indonesia. (2014). Infodatin: Situasi Kesehatan Ibu. Jakarta: Kementerian Kesehatan Republik Indonesia. Retrieved from http://www.depkes.go.id/resources/download/pus datin/infodatin/infodatin-ibu.pdf.

Kementerian Perencanaan Pembangunan Nasional. (2017). Ringkasan Metadata Indikator:Tujuan Pembangunan Berkelanjutan (TPB)/Sustainable Development Goals (SDGs) Indonesia. Jakarta:Kementerian Perencanaan Pembangunan Nasional.

Kurniati, A., Nadyah, \& Darmawansyih. (2019). Gambaran Faktor-Faktor yang Mempengaruhi Ibu Nifas Menggunakan Jasa Dukun di Wilayah Kerja Puskesmas Bontomarannu Kecamatan Galesong Selatan Kabupaten Takalar 2017. Jurnal Midwifery, 1(1), 58-67. Retrieved from http://journal.uinalauddin.ac.id/index.php/jmidwifery/article/view/7535

Lawson, G.W. \& Keirse, M.J.N.C. (2013). Reflections on the Maternal Mortality Millennium Goal. Birth Issues in Perinatal Health, 40(2), 96-102. Retrieved from http://europepmc.org/abstract/MED/24635463.

Menteri Kesehatan Republik Indonesia. (2016). Peraturan Menteri Kesehatan Republik Indonesia Nomor 43 Tahun 2016. Retrieved from http://peraturan.bpk.go.id/Home/Details/113091/permenkes-no-43tahun-2016.

Nahak, K.A. (2017). Hubungan Dukungan Suami dengan Kepatuhan melakukan Kunjungan ANC pada Ibu Hamil TM III di Puskesmas Sasi Kabupaten Timor Tengah Utara Tahun 2017. 26-35. Retrieved from http://ejournal.stikesborromeus.ac.id.

Ningrum, C.W. (2019). Hubungan Pengetahuan dan Sikap Ibu dengan Kepatuhan Kunjungan ANC di Kota Surakarta. Jurnal Media Kesehatan Masyarakat Indonesia, 10(6), i-11. doi: http://dx.doi.org/10.30597/mkmi.v10i4.496. 
Nurhidayanti, S., Margawati, A. \& Irene, M. (2018). Kepercayaan Masyarakat terhadap Penolong Persalinan di Wilayah Halmahera Utara. Jurnal Promosi Kesehatan Indonesia, 13(1), 46-60. doi: https://doi.org/10.14710/jpki.13.1.46-60.

Nurrizka, R.H., \& Wahyono, T.Y.M. (2018). Disparitas Kematian Maternal di Indonesia Studi Ekologi dengan Analisis Spasial. Jurnal MKMI, 14(2), 119-127. doi : http://dx.doi.org/10.30597/mkmi.v14i2.3630.

Putro, G. \& Maisya, I.B. (2018). Determinan Sosial dalam Kematian Maternal di RSUD dr. Abdoer Rahem Kabupaten Situbondo. Global Medical and Health Communi cation, 6(1), 74-82. doi: hhtp://dx.doi.org/10.29313/ gmhc.v6i1. 3274.

Rahmawati, P., Martini, S., \& Wahyuni, C.U. (2014). Analisis Determinan Kematian Maternal pada Masa Nifas di Kabupaten Sidoarjo Tahun 2012. Jurnal Berkala Epidemiologi, 2(1), 105-117. Retrieved from http://repository.unair.ac.id/id/eprint/38715.

Reinnisa, A., \& Indrawati, F. (2017). Persepsi Ibu Nifas tentang Pelayanan Postnatal Care dengan Kunjungan Ulang. Higeia Journal of Public Heallth Research and Development, 1(3), 33-42. Retrieved from https://journal. unnes.ac.id/sju/index.php/higeia/article/view/14047.

Saraswat, L., Ayansina, D.T., Cooper, K.G., Bhattacharya, S., Miligkos, D., Home, A.W., \& Bhattacharya, S.. (2017). Pregnancy Outcome in Women with Endometriosis: a National Record Linkage Study. BJOG:An International Journal of Obstetries and Gynaecology, 124(3), 444-452. doi: https://doi.org/10.1111/1471-0528.13920.

Suriani (2017). Analisis Faktor Kejadian Kematian Ibu di Kabupaten Sserang Banten. Prosiding Seminar Nasional IKAKESMADA "Peran Tenaga Kesehatan dalam Pelaksanaan SDGs". ISBN: 978-979-3812-41-0.

Sukma, F., Hidayati, E., dan Jamil, S.N. (2017). Asuhan Kebidanan pada Masa Nifas. Jakarta: Fakultas Kedokteran dan Kesehatan Universitas Muhammadiyah Jakarta.

Sumarmi, S. (2017). Model Sosio Ekologi Perilaku Kesehatan dan Pendekatan Continuum of Care untuk Menurunkan Angka Kematian Ibu. The Indonesian Journal of Public Health, 12(1), 129-141. doi: 10.20473/ijph.v12i1.2017.129-141.

Windarti, Y. \& Dewi, U.M. (2018). Pengaruh Paritas dan Media Konseling Masa Nifas terhadap Kemampuan Perawatan Mandiri Ibu Post Partum di BPM VIVI Surabaya. JHS:Journal of Health Science, 11(1), 28-32. doi: https://doi.org/10.33086/jhs.v11i1.547.

UNICEF Indonesia. (2012). Ringkasan Kajian:Kesehatan Ibu dan Anak. Jakarta: UNICEF Indonesia.

World Health Organization. (2016). Indicator and Monitoring Framework for The Global Strategy for Women's, Children's and Adolescents' Health (2016-2030). Genewa, Switzerland: World Health Organization. 